\title{
Oxygen consumption and heart rate obtained in a ramp protocol are equivalent during exercise session of rectangular loading at ventilatory thresholds for athletes
}

\section{Consumo de oxigênio e frequência cardíaca obtidos em um protocolo de rampa são equivalentes durante sessão de exercícios de carga retangular nos limiares ventilatórios para atletas}

\author{
Victor Hugo Gasparini Neto \\ (iD) https://orcid.org/0000-0002-4131-5004 \\ Paulo Azevedo 2 \\ (iD) https://orcid.org/0000-0002-4293-9214 \\ Luciana Carletti 1 \\ (iD) https://orcid.org/0000-0003-0085-1705 \\ Anselmo José Perez \\ (D) https://orcid.org/ 0000-0002-6777-4700
}

Abstract - Training near or at ventilatory threshold (VT) is an adequate stimulus to improve the thresholds for sedentary subjects, but a higher intensity is necessary for conditioned subjects. The choice of cardiopulmonary exercise testing $(\mathrm{CPx})$ protocol has an influence on $V T s$ identification and can reduce their reliability for exercise prescription. This study tested if $\mathrm{VO}_{2}$ and heart rate (HR) corresponding to first (VT1) and second ventilatory threshold (VT2) determined during a ramp protocol were equivalent to those observed in rectangular load exercises at the same intensity in runners elite athletes (EA) and non-athletes (NA). Eighteen health subjects were divided into two groups: $\mathrm{EA}\left(\mathrm{n}=9, \mathrm{VO} \mathrm{O}_{2 \mathrm{mx}} 68.6 \mathrm{~mL} \cdot \mathrm{kg}^{-1} \cdot \mathrm{min}^{-1}\right)$ and NA $\left(\mathrm{n}=9, \dot{\mathrm{VO}}{ }_{2 \max } 47.2 \mathrm{~mL} \cdot \mathrm{kg}^{-1} \cdot \mathrm{min}^{-1}\right)$. They performed $\mathrm{CPx}$ and $48 \mathrm{~h}$ and $96 \mathrm{~h}$ later, a continuous running lasting $1 \mathrm{~h}$ for VT1 and until exhaustion for VT2. The results showed that EA at VT1 session, presented delta differences for $\mathrm{VO}_{2}(+9.1 \%, \mathrm{p}=0.125)$ vs. NA $(+20.5 \%$, $\mathrm{p}=0.012)$. The Bland-Altman plots for VT1 presented biases of $(4.4 \pm 6.9)$ and $(5.5 \pm 5.6$ $\left.\mathrm{mLO}_{2} \cdot \mathrm{kg}^{-1} \cdot \mathrm{min}^{-1}\right)$ for $\mathrm{AE}$ and NA, respectively. In VT2, the $\mathrm{VO}_{2}$ and $\mathrm{HR}$ of the NA showed biases of $\left(0.4 \pm 2.9 \mathrm{mLO} \cdot \mathrm{kg}^{-1} \cdot \mathrm{min}^{-1}\right)$ and $(4.9 \pm 4.2 \mathrm{bpm})$. The ramp protocol used in this study was inappropriate for NA because it underestimates the values of $\mathrm{VO}_{2}$ and $\mathrm{HR}$ at VT1 found in the rectangular load exercise. The HR showed good agreement at VT2 with CPx and may be a good parameter for controlling exercise intensity.

Key words: Exercise testing, Continuous running, Training prescription, Runners, Elite athletes

Resumo - O treinamento no limiar ventilatório (LV) é um estimulo adequado para melhorar os limiares em individuos sedentários, entretanto uma maior intensidade é necessária para indivíduos condicionados. A escolha do protocolo de teste de exercicio cardiopulmonar (CPx) tem influência na identificação dos $L V$ e pode reduzir sua confiabilidade na prescrição do exercício. Este estudo testou se o $\mathrm{VO}_{2}$ e a frequência cardiaca (FC) correspondentes ao primeiro (LV1) e segundo limiar ventilatório (LV2) determinados durante um protocolo de rampa foram equivalentes àqueles observados em exercícios de carga retangular nas mesmas intensidades em atletas corredores de elite (AE) e não atletas (NA). Dezoito homens saudáveis foram divididos em dois grupos: $A E\left(n=9, \dot{V} O_{\text {max }} 68,6\right.$ $\left.\mathrm{mL} \cdot \mathrm{kg}^{-1} \cdot \mathrm{min}^{-1}\right)$ e $\mathrm{NA}\left(\mathrm{n}=9, \dot{V} \mathrm{O}_{2 \max } 47,2 \mathrm{~mL} \cdot \mathrm{kg}^{-1} \cdot \mathrm{min}^{-1}\right)$. Eles realizaram $\mathrm{CPx}$ e $48 \mathrm{~h}$ e $96 \mathrm{~h}$ depois, uma corrida contínua com duração de 1 h para o LV1 e até a exaustão para o LV2. O grupo AE na sessão LV1, apresentou diferenças de delta para $\dot{V} \mathrm{O}_{2}(+9,1 \%, p=0,125)$ vs. $N A(+20,5 \%, p=$ 0,012). Bland-Altman para LV1 apresentaram vieses de $(4,4 \pm 6,9)$ e $\left(5,5 \pm 5,6 \mathrm{mLO} \cdot \mathrm{kg}^{-1} \cdot \mathrm{min}^{-1}\right)$ para $A E$ e $N A$, respectivamente. No $L V 2$, o $\dot{V} \mathrm{O}_{2}$ e a $F C$ do $N A$ apresentaram vieses de $(0,4 \pm 2,9)$ $m L O_{2} \cdot \mathrm{kg}^{-1} \cdot \mathrm{min}^{-1}$ e $(4,9 \pm 4,2) \mathrm{bpm}$. O protocolo de rampa utilizado foi inadequado para $N A$ pois subestima os valores de $\dot{V O}_{2}$ e FC em LV1 encontrados no exercício de carga retangular. A FC exibiu boa concordância no LV2 e pode ser um bom parâmetro para controlar a intensidade do exercício.

Palavras-chave: Teste de esforço, Corrida contínua, Prescrição de treinamento, Corredores, Atletas de elite
1 Federal University of Espírito Santo. Center of Sports and Physical Education. Vitória, ES. Brazil.

2 Federal University of São Paulo. Graduate Program in Human Movement and Rehabilitation Sciences. Exercise Physiology Studies and Research Group. Santos, SP. Brazil.

Received: 19 July 2018 Accepted: 13 March 2019

How to cite this article Gasparini Neto VH, Azevedo P, Carletti L, Perez AJ. Oxygen consumption and heart rate obtained in a ramp protocol are equivalent during exercise session of rectangular loading at ventilatory thresholds for athletes. Rev Bras Cineantropom Desempenho Hum 2019, 21:e58285. D0l: http://dx.doi.org/ 10.1590/1980-0037.2019v21e58285

Copyright: This work is licensed under a Creative Commons Attribution 4.0 International License. 


\section{INTRODUCTION}

The cardiopulmonary exercise test $(\mathrm{CPx})$ is the gold standard when determining maximal oxygen uptake $\left(\mathrm{VO}_{2 \max }\right)$ and in the prognosis and diagnosis of cardiopulmonary disease ${ }^{1}$. Individuals with different levels of physical performance like athletes and non-athletes perform $\mathrm{CPx}$ tests to improve training prescriptions obtained from $\mathrm{VO}_{2 \max }$ fractions estimated by ventilatory threshold (VT), as submaximal control parameters during prolonged effort ${ }^{2,3}$. Coaches', athletes' and exercise physiologists' interest in determining and using VT is due to its strong correlation with lactate threshold and because it is a better performance prediction parameter than $\mathrm{VO}_{2 \max }{ }^{1-4}$.

$\mathrm{VT}$ intensity in relation to running speed, $\% \mathrm{VO}_{2 \max }$ and heart rate (HR) are all used to control intensity. However, the choice of ergometer and protocol used in CPx can affect the identification of the intensity associated with VTs and thereby reduce the reliability and reproducibility ${ }^{5}$. Ramp protocols allow individualisation of the test, more uniform haemodynamic responses and gas exchange and better prognosis, diagnosis and measurement of ventilatory thresholds than traditional staggered protocols ${ }^{6}$. However, the short duration of load changes in the ramp protocol may not show good reproducibility for prescription load on long-lasting exercise.

CPx performed on a cycle ergometer with smoothed load increments of between 20 and $50 \mathrm{~W} \cdot \mathrm{min}^{-1}$ has shown reliable first ventilatory threshold (VT1) values and good VT1 and second ventilatory threshold (VT2) reproducibility in testing and retesting in individuals at different fitness levels ${ }^{5-7}$. However, protocols with large or uneven load increments (increments $>50$ to $100 \mathrm{~W} \cdot \mathrm{min}^{-1}$ ) lead to a delay in $\mathrm{O}_{2}$ intake response in relation to the cycle ergometer workload and may overestimate $\mathrm{VO}_{2 \max }$ on the treadmill ${ }^{5}$. A delay of 45 seconds or more in VT1 identification relating to workload was found in Davis et al. ${ }^{5}$ therefore, these authors suggest caution when relating these values to $\mathrm{VO}_{2}$ or $\mathrm{HR}$ for exercise prescription or performance evaluation ${ }^{5,6,8}$. Ramp protocols offer a means of overcoming the limitations of standard incremental protocols and, when the goal is to optimise exercise prescription, it is important to consider the difference between the values obtained in CPx and in the exercise session and whether this difference represents just a random fluctuation or a real change that requires the training load to be changed ${ }^{9}$.

It is known that athletes and non-athletes show stability in cardiorespiratory variables during an exercise session of constant load at the intensity of the $V T 1^{10}$. However, it is still unclear whether non-athletes present the same magnitude of response of the exercise prescription variables such as $\mathrm{VO}_{2}$ and heart rate when compared between $\mathrm{CPx}$ and the constant loading session. It is possible that athletes present lower metabolic stress to sustain the load at the threshold due to better running economy ${ }^{11}$, lower systolic volume ${ }^{12}$. When compared to non-athletes was demonstrate previously that training at an intensity near or at ventilatory threshold is an adequate training stimulus for improving the thresholds for sedentary subjects, but a higher intensity may 
be necessary for conditioned subjects ${ }^{13}$. Therefore, the aim of this study was to test whether the ventilatory and metabolic variables corresponding to VT1 and VT2 determined during the ramp protocol are equivalent to those observed in a constant load exercise at the same intensity in both elite athletes and nonathletes. We hypothesized that subjects with higher fitness level (athletes) will present more equivalence at metabolic and ventilatory variables during constant load exercise than subjects with lower fitness level (non-athletes).

\section{METHOD}

\section{Participants}

A total of 18 subjects at different levels of cardiopulmonary performance, who were street runners with at least 1 year of experience, were evaluated and (characteristics of subjects are shown in Table 1). The subjects were selected by convenience and divided into two groups: 9 elite athletes (EA) that were highly trained and participated in races of 5 and $10 \mathrm{~km}$, and 9 non-athletes (NA) classified a recreationally runner. A sample size calculation was used in accordance with the expected changes in $\mathrm{VO}_{2 \max }$, with $\mathrm{SD}$ of $8 \mathrm{~mL} \cdot \mathrm{kg}^{-1} \cdot \mathrm{min}^{-1}$ between groups $(6)^{14}$ using independent $\mathrm{t}$ test with $(z \alpha=1.96$ and $z \beta=0.84)$. The volunteers were informed to abstained drink coffee, alcohol and exhaustive exercise almost $24 \mathrm{~h}$ before visit at lab. At the first visit, they came at morning between 9 and $11 \mathrm{~h}$ and performing anthropometry and cardiopulmonary exercise testing $(\mathrm{CPx})$. The second and third visit, after $48 \mathrm{~h}$ they run at first and second VT speed. The procedures were performed in accordance with local resolution no. 466, December 12, 2012, and were approved by the Federal University of Espírito Santo (UFES) ethics committee under $n^{\circ} .261 .897$ of 02/05/2013. All subjects were informed about and familiarised with the experimental procedures, risks and benefits and signed terms of written consent $t^{15}$.

\section{Procedures}

The subjects visited the laboratory on three occasions separated by a minimum of 48 hours. Anthropometric and CPx were performed on the first visit, a 1-hour exercise session at VT1 speed was performed on the second visit and an exercise session at a speed of VT2, to volitional exhaustion, was performed on the third visit. $\mathrm{HR}$ and $\mathrm{VO}_{2}$ was monitored in all visits. In addition, subjects were instructed to avoid strenuous exercise in the 24 hours preceding the laboratory visit. Subjects with cardiometabolic or uncontrolled musculoskeletal diseases that would prevent them from performing the tests were excluded. One EA group subject was excluded from the analysis due to technical problems with the heart rate monitor.

\section{Anthropometrics}

Body weight and height were measured using a digital scale with a onemillimeter precision stadiometer with a maximum capacity of $201 \mathrm{~kg}$ and a sensitivity of 50 grams (Marte Científica, L200, São Paulo). It is 
possible to calculate the Body Mass Index (BMI). The anthropometric measurements were performed by a same experienced evaluator who used a scientific plicometer with a sensitivity of $0.1 \mathrm{~mm}$ and reading range of $85 \mathrm{~mm}$ (Mitutoyo / Cescorf, RS), including 7 skinfolds (triceps, subscapular, pectoral, supra-iliac, abdominal and thigh). For perimetry, was used a $2 \mathrm{~m}$ of flexible steel with resolution in $\mathrm{mm}$ (Cescorf, RS).

\section{Cardiopulmonary Exercise Testing}

Initially, the subjects remained for five minutes at rest in supine position. The 12-lead resting ECG (MICROMED, Brasília, Brazil) was performed to detect any disturbance that contraindicated maximum effort. Electrocardiographic recording during pre-exertion (standing on the treadmill) and exertion (simultaneously with $\mathrm{CPx}$ ) was performed using three simultaneous leads (MC5, D2M and V2M).

The CPx was performed on a motorised treadmill (Inbrasport Super ATL, Porto Alegre, Brazil) with fixed $1 \%$ slope, following a ramp protocol with an estimated test duration of 10 to 12 minutes. The speed was gradually increased until exhaustion. The EA group started with a speed of $8 \mathrm{~km} \cdot \mathrm{h}^{-1}$, and the NA group commenced at a speed of $5 \mathrm{~km} \cdot \mathrm{h}^{-1}$, with an increase of 0.7 to $1 \mathrm{~km} \cdot \mathrm{h}^{-1}$ every minute. A metabolic gas analyser (Cortex Metalyzer 3B, Germany) was used, with breath by breath collection and calibration with ambient and known gases $\left(11.97 \% \mathrm{O}_{2}\right.$ and $\left.4.95 \% \mathrm{CO}_{2}\right)$. The volume was calibrated with a 3-L syringe. The temperature was controlled between 22 and $25^{\circ} \mathrm{C}$. The test was conducted by a exercise physiologist and monitored by a cardiologist. At least three of the following criteria were considered in recognising the maximum test: a) volitional exhaustion; b) achieving HR $\geq 90 \%$ of the predicted maximum (220-age); c) respiratory exchange ratio (RER) of $1.05^{16}$ or above; and d) $\mathrm{VO}_{2 \max }$ plateau ${ }^{1,17}$. The maximum velocity (Vmax) was determined to be the rate at which the $\mathrm{VO}_{2 \max }$ was identified.

\section{Ventilatory Thresholds Identification}

Three evaluators experienced in exercise physiology analysed the criteria of ventilatory thresholds blindly and independently. The intraclass correlation coefficient was used with values varying between $(0.89-0.97)$. Agreement values between at two evaluators were considered. VT1 was identified by different criteria: 1 - at the lowest point followed by an exponential increase in ventilatory oxygen equivalent $\left(\mathrm{VE} / \mathrm{VO}_{2}\right)$ without an increase in the ventilatory carbon dioxide equivalent $\left(\overrightarrow{\mathrm{V}} / \overrightarrow{\mathrm{V} C \mathrm{CO}_{2}}\right) ; 2-\mathrm{V}$-slope method, indicating the point of intersection with loss of $\mathrm{VCO}_{2} / \mathrm{VO}_{2}$ linearity; and 3from abrupt increases in $\mathrm{VE}$ and end-tidal oxygen tension $\left(\mathrm{P}_{\mathrm{ET}} \mathrm{O}_{2}\right)^{18}$. VT2 was considered the point of the increase $\mathrm{VE} / \mathrm{VCO}_{2}$ level, and beyond the point of gradual decrease of end-tidal carbon dioxide tension $\left(\mathrm{P}_{\mathrm{ET}} \mathrm{CO}_{2}\right)^{18-19}$.

\section{Exercise Sessions}

The exercise sessions was made between $48 \mathrm{~h}$ and $96 \mathrm{~h}$ after $\mathrm{CPx}$. The sessions commenced whit 5-minute warm-up, at an intensity of $20 \%$ below 
the VT1 speed achieved in the CPx and free static stretches. The volunteers then remained standing for 2 minutes on the treadmill after the equipment calibration procedure, adjustments to the treadmill, mask and belt POLAR T31- CODED (Polar, Kempele, Finland) were performed. The stipulated speed was then adjusted manually. After 10 to 15 seconds of stabilisation, the subjects ran with continuous measurement of expired gases and a maximum duration of 1 hour in VT1. Forty-eight hours thereafter, the same procedures were performed in VT2 until volitional exhaustion.

\section{Statistical Analisys}

The Kolmogorov-Smirnov test was used to evaluate data normality. Data were subjected to descriptive analysis (means \pm standard deviations). In the VT1 and VT2 exercise sessions, the means were calculated every 2 minutes and every 30 seconds, respectively, and were analysed after the 3rd minute. The Student's paired $t$ test was used to compare CPx and Session means between groups. Comparison of values from ventilatory and metabolic variables relative to $\mathrm{VT} 1_{\text {cpx }}$ and $\mathrm{VT} 2_{\mathrm{cpx}}$ and exercise session relative to $\mathrm{VT} 1_{\text {session }}$ and VT2 $2_{\text {session. }}$ Also the delta (absolute and percentage) was used to compare the differences in values between CPx and exercise sessions (Session - CPx). The coefficient of variation was calculated using the formula CV $=100 \mathrm{x}$ (SD / mean). The Bland-Altman analysis in $\operatorname{Excel}^{\mathrm{TM}}$ was used to evaluate the CPx's $\mathrm{VO}_{2}$ and $\mathrm{HR}$ agreement thresholds with the exercise sessions in VT1 and VT2 ${ }^{20,21}$. Hedges' $g$ (presented by "g") was used to evaluate the effect magnitude, based on an arbitrary scale of 0.2, 0.5, 0.8 and 1.3, indicating mild, moderate, large and very large effects, respectively ${ }^{22}$. SigmaStat $(3.5$ software (Systat Software, Germany, 2006) was used for inferential analysis, and statistical significance was accepted at the $p \leq 0.05$.

\section{RESULTS}

The total test time $12 \pm 0.9$ and $11 \pm 1.1 \mathrm{~min}$ of $\mathrm{CPx}$ did not differ statistically in EA and NA respectively $(p=0.204, g=0.95)$. Seventeen subjects performed 1 hour of exercise in the VT1 $1_{\text {session }}$. As expected, the EA group had higher speed relating to VT1, VT2 and Vmax and for $\mathrm{VO}_{2 \mathrm{VT} 1}, \mathrm{VO}_{2 \mathrm{VT} 2}$ and $\mathrm{VO}_{2 \max }(p \leq 0.05)$. RER was higher for the EA group in VT1 $(p \leq$ $0.05)$. There were no differences in HR values between the groups at any intensity (Table 1).

During the constant load exercise in the $\mathrm{VT} 1_{\text {session }}$, the EA group obtained higher $\mathrm{VO}_{2}(8.1 \%)$ and $\mathrm{HR}(3.9 \%)$ when compared to the $\mathrm{CPx}$ values $(p \leq 0.05, \mathrm{~g}=1.067)$. In the NA group, the differences were $22.2 \%$ greater in $\mathrm{VO}_{2}$ and $10.6 \%$ greater in $\mathrm{HR}$ than in $\mathrm{CPx}$, which produced a very large effect size $(p \leq 0.05, \mathrm{~g}=1.591)$ (Table 1$)$.

In the VT2 ${ }_{\text {session }}$, subjects exercised until volitional fatigue. The exercise times ranged from (4 to 25 minutes) for EA and (5.3 to 21 minutes) for NA, but without significant differences in mean time, with $10 \pm 6.8$ for $\mathrm{EA}$ and $12 \pm 5.9$ minutes for NA $(p=0.55 ; \mathrm{g}=-0.30)$. For the VT2 
both groups exhibited no differences $(p>0.05)$ in $\mathrm{HR}$ and $\mathrm{VO}_{2}$. (Table 2).

Table 1. Subject characteristics and comparison of physiological and performance data obtained from the CPx test. (NA = Non-Athletes, EA= Elite Athletes)

\begin{tabular}{|c|c|c|c|c|}
\hline Variables & $N A(n=9)$ & $\mathrm{EA}(\mathrm{n}=9)$ & CV\% (NA/EA) & $p$ value \\
\hline Weight (kg) & $82.1 \pm 9.9$ & $61.8 \pm 4.5^{\star}$ & - & $<0.001$ \\
\hline Height (m) & $1.75 \pm 0.09$ & $1.71 \pm 0.05$ & - & 0.311 \\
\hline Age (years) & $32 \pm 10$ & $31 \pm 5.7$ & - & 0.574 \\
\hline BMI $\left(\mathrm{kg} \cdot \mathrm{m}^{2}\right)$ & $26.8 \pm 2.2$ & $21.0 \pm 1.1^{\star}$ & - & $<0.001$ \\
\hline$\sum$ Skinfold (mm) & $134.8 \pm 57.0$ & $40.3 \pm 10.5^{\star}$ & - & $<0.001$ \\
\hline $\operatorname{vVT1}\left(\mathrm{km} \cdot \mathrm{h}^{-1}\right)$ & $9.2 \pm 1.3$ & $15.6 \pm 1.7^{\star}$ & $13.8 / 11.0 \%$ & $<0.001$ \\
\hline \% Vmax (VT1) & $57.1 \pm 6.9 \%$ & $70.0 \pm 6.8 \%$ & - & - \\
\hline vVT2 $\left(\mathrm{km} \cdot \mathrm{h}^{-1}\right)$ & $13.0 \pm 1.8$ & $19.5 \pm 1.3^{\star}$ & $14.4 / 10.8 \%$ & $<0.001$ \\
\hline \% Vmax (VT2) & $80.4 \pm 9.0 \%$ & $87.7 \pm 4.1 \%$ & - & - \\
\hline $\operatorname{Vmax}\left(\mathrm{km} \cdot \mathrm{h}^{-1}\right)$ & $16.2 \pm 1.1$ & $22.2 \pm 0.9^{*}$ & $6.8 / 4.0 \%$ & $<0.001$ \\
\hline$\dot{\mathrm{V}} \mathrm{O}_{2 \mathrm{VT} 1}\left(\mathrm{~mL} \cdot \mathrm{kg}^{-1} \cdot \mathrm{min}^{-1}\right)$ & $27.3 \pm 4.9$ & $49.3 \pm 4.8^{*}$ & $13.0 / 8.8 \%$ & $<0.001$ \\
\hline$\% \dot{\mathrm{V}} \mathrm{O}_{2 \max }(\mathrm{VT} 1)$ & $61.8 \pm 8.9 \%$ & $72.7 \pm 3.8 \%$ & - & - \\
\hline$\dot{\mathrm{V}} \mathrm{O}_{2 \mathrm{VT} 2}\left(\mathrm{~mL} \cdot \mathrm{kg}^{-1} \cdot \mathrm{min}^{-1}\right)$ & $39.6 \pm 3.8$ & $62.7 \pm 5.2^{*}$ & $9.7 / 8.3 \%$ & $<0.001$ \\
\hline$\% \dot{V}_{2 \max }(\mathrm{VT} 2)$ & $84.8 \pm 7.5 \%$ & $90.4 \pm 5.6 \%$ & - & - \\
\hline$\dot{\mathrm{V}} \mathrm{O}_{2 \max }\left(\mathrm{mL} \cdot \mathrm{kg}^{-1} \cdot \mathrm{min}^{-1}\right)$ & $47.2 \pm 4.4$ & $68.6 \pm 3.2^{*}$ & $9.3 / 4.6 \%$ & $<0.001$ \\
\hline $\mathrm{HR}_{\mathrm{VT} 1}\left(\right.$ beats. $\mathrm{min}^{-1}$ ) & $141 \pm 15$ & $151 \pm 8.5$ & $11.8 / 3.5 \%$ & 0.109 \\
\hline$\% \mathrm{HR}_{\max }(\mathrm{VT} 1)$ & $76.0 \pm 5.4 \%$ & $85.5 \pm 4.2 \%$ & - & - \\
\hline $\mathrm{HR}_{\mathrm{VT} 2}$ (beats. $\mathrm{min}^{-1}$ ) & $171.0 \pm 11.3$ & $170.0 \pm 8.7$ & $6.6 / 5.1 \%$ & 0.945 \\
\hline$\% \mathrm{HR}_{\max }(\mathrm{VT} 2)$ & $91.4 \pm 4.0 \%$ & $94.9 \pm 2.4 \%$ & - & - \\
\hline $\mathrm{HR}_{\max }$ (beats.min-1) & $188 \pm 14.5$ & $184 \pm 14.8$ & $7.7 / 8.0 \%$ & 0.528 \\
\hline $\mathrm{RER}_{\mathrm{VT} 1}$ & $0.79 \pm 0.08$ & $0.89 \pm 0.04^{*}$ & $10.0 / 4.1 \%$ & 0.005 \\
\hline $\mathrm{RER}_{\mathrm{vT} 2}$ & $0.93 \pm 0.06$ & $0.98 \pm 0.04$ & $6.4 / 4.1 \%$ & 0.072 \\
\hline $\mathrm{RER}_{\max }$ & $1.09 \pm 0.03$ & $1.06 \pm 0.05$ & $4.8 / 3.0 \%$ & 0.103 \\
\hline
\end{tabular}

Note. Mean \pm SD. NA- Non-Athletes; EA - Elite athletes; VVT1 and vVT2 - Corresponding the velocity of first and second ventilatory thresholds; Vmax - Corresponding velocity on V02max;

Table 2. Comparison of values (Two sample $t$ test) from ventilatory and metabolic variables relative to VT1 $1_{c p x}$ and VT2 $2_{c p x}$ and exercise session relative to $V T 1_{\text {session }}$ and VT2 $2_{\text {session }}$ in the $E A(n=9)$ and NA $(n=9)$ groups.

\begin{tabular}{|c|c|c|c|c|c|c|c|}
\hline Groups & & Variables & $\mathrm{CPx}$ & Session & Delta $\Delta$ & $\boldsymbol{p}$ value & $E S(g)$ \\
\hline \multirow{4}{*}{ VT1 } & \multirow{2}{*}{ EA } & $\mathrm{VO}_{2}\left(\mathrm{~mL} \cdot \mathrm{kg}^{-1} \cdot \mathrm{min}^{-1}\right)$ & $49.3 \pm 4.8$ & $53.8 \pm 6.7$ & $4.4 \pm 6.8(+9.1 \%)$ & 0.125 & 0.747 \\
\hline & & HR (beats. $\mathrm{min}^{-1}$ ) & $151.0 \pm 8.5$ & $159.0 \pm 12.7$ & $8.0 \pm 7.1(+5.3 \%)$ & 0.170 & 0.666 \\
\hline & \multirow{2}{*}{ NA } & $\mathrm{VO}_{2}\left(\mathrm{~mL} \cdot \mathrm{kg}^{-1} \cdot \mathrm{min}^{-1}\right)$ & $27.3 \pm 4.9$ & $32.9 \pm 3.1^{*}$ & $5.5 \pm 5.6(+20.5 \%)$ & 0.012 & 1.346 \\
\hline & & HR (beats.min ${ }^{-1}$ ) & $141.0 \pm 15.0$ & $157.0 \pm 15.7^{*}$ & $16.0 \pm 24.2(+11.3 \%)$ & 0.042 & 1.015 \\
\hline \multirow{4}{*}{ VT2 } & \multirow{2}{*}{ EA } & $\mathrm{VO}_{2}\left(\mathrm{~mL} \cdot \mathrm{kg}^{-1} \cdot \mathrm{min}^{-1}\right)$ & $62.7 \pm 5.2$ & $64.1 \pm 5.0$ & $1.4 \pm 5.7(+2.2 \%)$ & 0.568 & 0.000 \\
\hline & & HR (beats. $\mathrm{min}^{-1}$ ) & $170.0 \pm 8.7$ & $170.0 \pm 7.0$ & $0.5 \pm 7.0(+0.6 \%)$ & 0.902 & 0.126 \\
\hline & \multirow{2}{*}{ NA } & $\mathrm{VO}_{2}\left(\mathrm{~mL} \cdot \mathrm{kg}^{-1} \cdot \mathrm{min}^{-1}\right)$ & $39.6 \pm 3.8$ & $39.9 \pm 4.6$ & $0.39 \pm 2.9(+0.7 \%)$ & 0.849 & 0.000 \\
\hline & & HR (beats. $\min ^{-1}$ ) & $171.0 \pm 11.3$ & $176.0 \pm 10.1$ & $5.0 \pm 4.1(+3.1 \%)$ & 0.332 & 0.453 \\
\hline
\end{tabular}

Note. Means \pm SD. NA - Non-Athletes; EA - Elite Athletes; Delta $\Delta-$ Difference in absolute and relative (\%) values from the VT1 corresponding to the first ventilatory threshold and the VT2 ${ }_{\text {session }}$ corresponding to the second ventilatory threshold vs. CPx; * $p \leq 0.05$; $\mathrm{ES}(\mathrm{g})$ - effect size - Hedges $g$.

HRmax - Maximal heart rate; RERmax - Maximal respiratory exchange ratio; CPx; ${ }^{*} \mathrm{p} \leq 0.05$; CV $(\%)$ - Coefficient of variation.

The Bland-Altman analysis comparing $\mathrm{CPx}$ and constant load exercise sessions revealed differences in means (bias) of $\mathrm{VO}_{2}$ and $\mathrm{HR}$ for $\mathrm{VT} 1$ and VT2 between groups (Figure 1). 


\section{VT1 - Ventilatory Threshold 1}
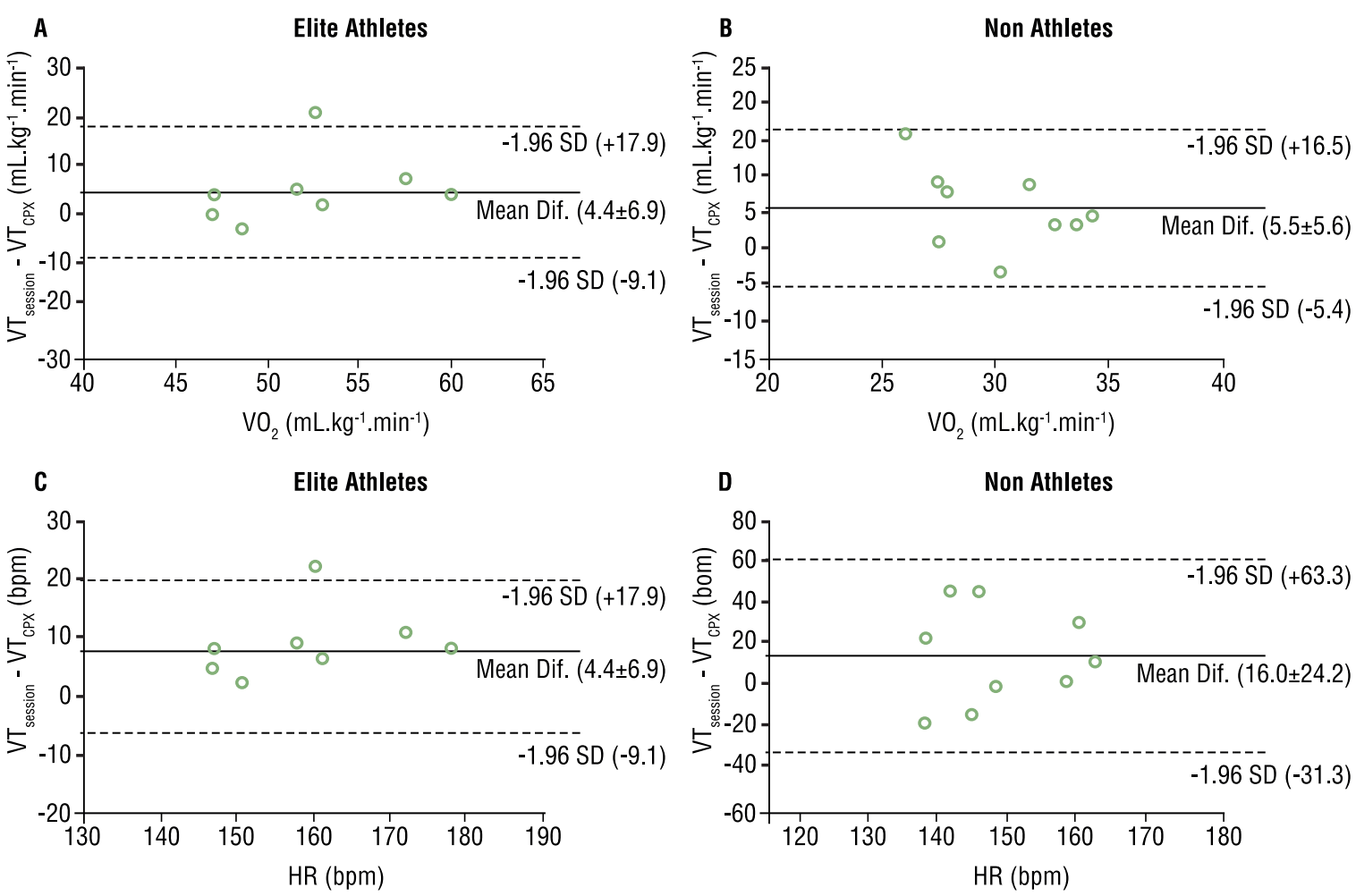

VT2 - Ventilatory Threshold 2
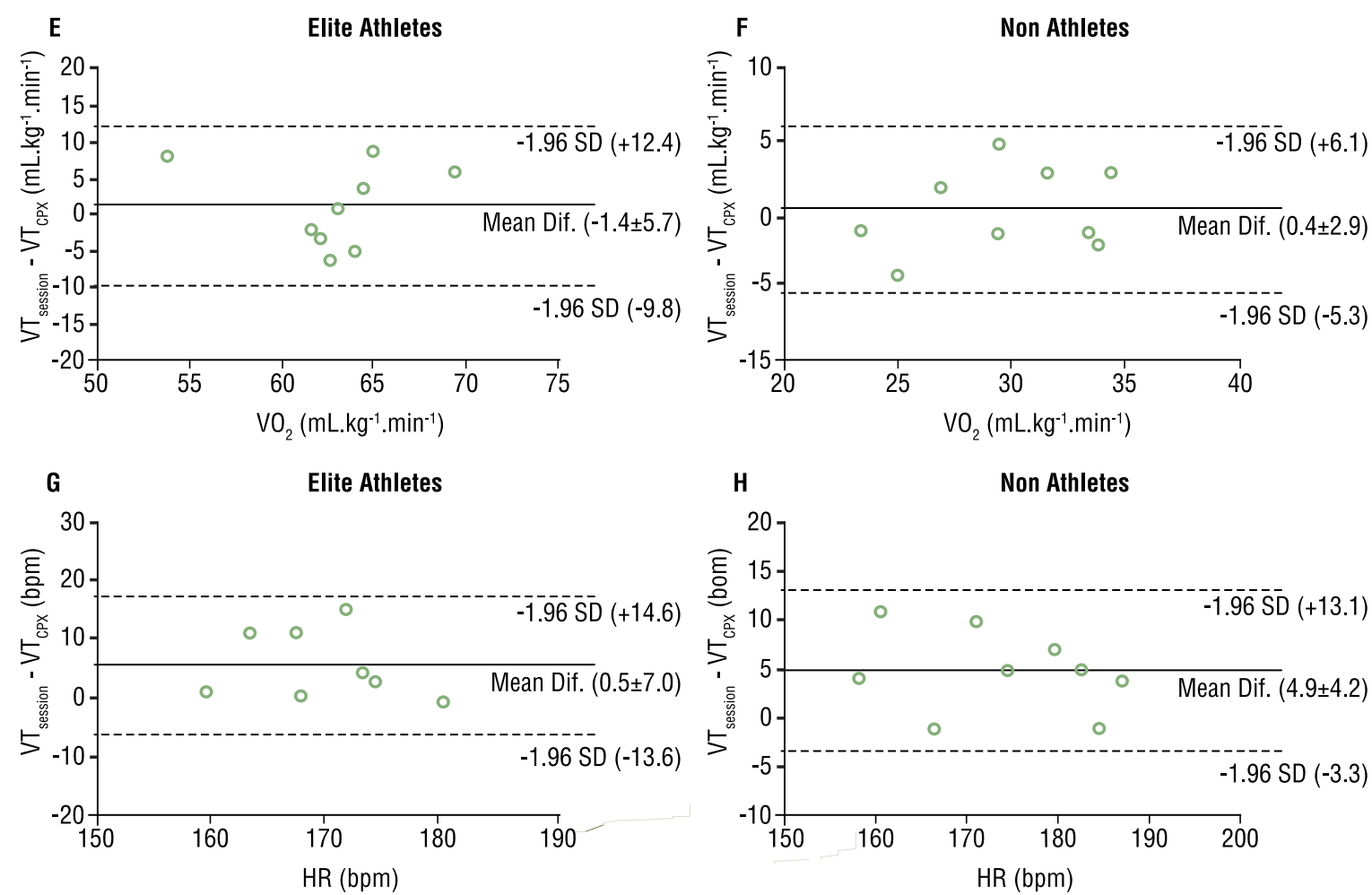

Figure 1. Bland-Altman plots. Agreement limits of $\mathrm{VO}_{2}$ and $\mathrm{HR}$ relative to $\mathrm{VT1}$, VT2 and $\mathrm{VT1}$, VT2 from EA and NA respectively. (A) and $(C)$ showing $\mathrm{VO}_{2}$ and $\mathrm{HR}$ values from the $\mathrm{AE}$ group. (B) and (D) showing $\mathrm{VO}_{2}^{\text {session }}$ and $\mathrm{HR}$ values from the NA group at the VT1. (E) and $(\mathrm{F})$ showing $\mathrm{VO}_{2}$ and $\mathrm{HR}$ values from the $\mathrm{AE}$ group. $(\mathrm{G})$ and $(\mathrm{H})$ showing $\mathrm{VO}_{2}$ and $\mathrm{HR}$ values from the NA group at the VT2. The $\mathrm{Y}$ axis shows the difference between $V T_{\text {session }}$ and $V T_{\text {cpx }}$. The abscissa axis represents the average of $V T_{\text {session }}$ and $V T_{\text {cpx }}(A+B) / 2$. VT1 - Relative to first ventilatory threshold; VT2 - Relative to second ventilatory threshold. Dotted lines show the limits of agreement (LOA); continuous lines show the mean differences (systematic biases). 


\section{DISCUSSION}

The aim of the present study was to evaluate whether the ventilatory and metabolic variables corresponding to VT1 and VT2 determined during the ramp protocol are equivalent to those observed in a rectangular load exercise at the same intensity in both elite athletes and non-athletes. The main find of this study shown that the large differences in $\mathrm{VO}_{2}$ and $\mathrm{HR}$ in the $\mathrm{VT} 1_{\text {session }}$ exhibit low agreement with the CPx in the NA group that confirmed our initial hypothesis. Also, despite the large difference in body weight between groups, the relative intensity of exercise was similar.

Variations of up to $8 \%$ in submaximal $\mathrm{VO}_{2}$ are considered to be expected biological variations ${ }^{23}$ but did not occur for NA in VT1 $1_{\text {session }}$. Furthermore, $\mathrm{HR}$ is considered the most common variable for physical exercise prescription and exhibited values with over $8 \%$ difference at VT $1_{\text {session }}$ for NA only and the Bland-Altman analysis showing greater agreement for EA, with biases of $5.5 \pm 9.2 \mathrm{bpm}$.

Previous studies have shown that in physically active individuals, deviations of $10 \mathrm{bpm}$ above and below the VT1 values could be identified in a single $\mathrm{CPx}$ with a ramp protocol ${ }^{8}$. These results show that the use of $\mathrm{HR}$ is not appropriate for intensity control. Such fluctuations may occur due to cardiac drift ${ }^{12}$. This phenomenon can occur in air-conditioned environments, usually after 10 minutes of moderate-intensity exercise, leading to an increase in skin blood flow, which reduces the end-diastolic volume, left ventricle filling pressure and systolic volume ${ }^{12}$. Therefore, the HR increases to maintain cardiac output along with maintenance of exercise ${ }^{12}$. Given that the specific nature of the exercise and ecological validity are important to allow coaches and trainers access to the ventilatory and metabolic threshold values and that these measures are used in an athlete's exercise prescription, HR is not an appropriate means of prescription and control for training sessions corresponding to VT1 for NA.

In addition to being a better sports performance predictor than $\mathrm{VO}_{2 \max }$, VT1 is an important tool for determining physical training intensity ${ }^{1,13}$. Denis et al. ${ }^{24}$ showed that physical training performed at VT1 and VT2 intensities increased $\% \mathrm{VO}_{2 \max }$ by $17 \%$ and $9 \%$ due to a delay in the formation of lactate at the beginning of an incremental test, with an increased tolerance to acidosis due to the buffering of $\mathrm{H}+$ ions by sodium bicarbonate ${ }^{24}$.

Classical studies have evaluated the importance of the particular ergometer and protocol used in the determination of thresholds and $\mathrm{VO}_{2 \max }{ }^{25}$. Cyclists and runners have shown different VT1 values when using a cycle ergometer for runners and a treadmill for cyclists due to the different patterns of muscle recruitment ${ }^{25}$. Furthermore, factors such as the detection method, test protocol and evaluator can affect the identification of VT. The choice of protocol used in CPx may affect VT1 value variation by up to $82 \%$ and the method with the highest ICC (0.92) is the V-Slope $(17)^{26}$. Hansen et al. ${ }^{27}$ evaluated heart disease patients with and without training on the treadmill and cycle ergometer and identified low agreement 
in VT1 in individuals with lower fitness levels. These findings resemble those of our study, although the authors ${ }^{27}$ used a modified Bruce protocol, which increases the chances of a smaller agreement in $\mathrm{VO}_{2}$. Furthermore, our data show that the ramp protocol underestimates VT1. Studies using ramp protocols with large or unequal load increments have demonstrated that these conditions lead to an interruption in the linear relationship between $\mathrm{VO}_{2}$ and workload ${ }^{25}$ suggesting cautious when interpreting these values at an exercise prescription. In contrast to these findings, protocols with smoothed load increments recorded reliable VT1 and produced good reproducibility of both VTs in testing and retesting of individuals at different fitness levels ${ }^{7,9}$. Our study compared CPx with VT1 and VT2 exercise sessions at different fitness levels, contributing, in a practical way, to the individualised prescription of physical exercise. Another point to note is that we used the Bland-Altman method to evaluate differences and agreements between $\mathrm{CPx}$ and exercise session values, whereas some previous studies used only correlation analysis. The latter reduces external validity, as it analyses the association between variables rather than the differences between them.

We used three methods in combination to identify VTs: ventilatory equivalent, the $\mathrm{V}$-slope and a visual method based on an individualised ramp protocol with increments from 0.7 to $1 \mathrm{~km} \cdot \mathrm{h}^{-1}$ every minute, which has better reproducibility in the identification and subsequent use of ventilatory thresholds than staggered protocols ${ }^{26}$. Our findings suggest that the use of CPx allowed us to identify good agreement in $\mathrm{HR}$ and $\mathrm{VO}_{2}$ values in street runner athletes in VT1 and VT2, based on both central physiological adaptations (e.g., increased maximum cardiac output) and peripheral ones (e.g., increased $\mathrm{O}_{2}$ supply and running economy) ${ }^{28}$. HR has been shown to be a good parameter in controlling an exercise session in VT2 for EA and NA. Our study has some limitations. We did not randomize the days of the exercise sessions, nor did we perform measurements of blood lactate. However, despite this, the identification of ventilatory thresholds presented high reliability among the three evaluators. Some authors suggest the use of deltas\% above VT1, determination of critical $\mathrm{VO}_{2}$ and MSSL for exercise prescription ${ }^{28}$. These methodologies, despite being gold standard in the determination of exercise intensities, have limitations of application, having an invasive bias and requiring 3 to 5 days for the presence of the subject in the laboratory, which reinforces the use of ventilatory thresholds. Therefore, the ramp protocol, is preferable than step protocol because the relationship with $\mathrm{VO}_{2}$ increment is more smoothly ${ }^{25}$. Also, when blood lactate concentration increases relative to baseline, the associated increase in hydrogen ion is buffered causing an increased production of $\mathrm{CO}_{2}$ and a disproportionate increase in $\mathrm{VCO}_{2}$ relative to $\mathrm{VO}_{2}$. At the same time, the alveolar and total ventilation increases to remove excess $\mathrm{CO}_{2}$, and the $\vec{V}_{\mathrm{E}} / \vec{V}$ $\mathrm{O}_{2}$ slope increases (VT1). After that, occurs a plateau in end-tidal partial pressure of $\mathrm{CO}_{2}\left(\mathrm{P}_{\mathrm{ET}} \mathrm{CO}_{2}\right)$, termed the isocapnic buffering period. This phenomenon is less discernible or not present in step prolonged protocol ${ }^{28}$. 
Also, the fitness level and increased rate in the ramp protocol achieved in our results indicate that the interpretation of VT values is affected after $\mathrm{CPx}$; these findings may affect the individualised prescription of physical training. It is suggested that studies evaluating protocols using smoother increments on a treadmill are needed to verify the best protocol to be used for the proper identification and use of VTs. In addition, the protocol used in our study does not apply to prescribing exercise at the intensities associated with VT1 in NA and EA, as $75 \%$ of the training volume within a periodisation is prescribed at intensities below, or close to VT1 ${ }^{30}$. The results from present study yield some recommendations and practical applications. When compared elite athletes (EA) with non-athletes (NA), a better agreement regarding $\mathrm{VO}_{2}$ and $\mathrm{HR}$ values are relative to VT2 intensities. The HR exhibited good agreement with $\mathrm{CPx}$ and may be a good parameter for controlling exercise intensity and finally, VT1 intensity had poorly agreement and can affect the exercise prescription specially in NA.

\section{CONCLUSION}

The ramp protocol used in this study was inappropriate because it underestimates the values found in the constant load exercise and does not meet the criterion of being an individualised test. In addition, a lower level of physical performance can affect VT1 with rectangular load exercise sessions.

\section{COMPLIANCE WITH ETHICAL STANDARDS}

\section{Funding}

This research did not receive any specific grant from funding agencies in the public, commercial, or not-for-profit sectors. This study was funded by the authors.

\section{Ethical approval}

Ethical approval was obtained from the local Human Research Ethics Committee - Federal University of Espírito Santo (UFES) and the protocol (no. 261.897) was written in accordance with the standards set by the Declaration of Helsinki.

\section{Conflict of interest statement}

The authors have no conflict of interests to declare.

\section{Author Contributions}

Conceived and designed the experiments: VHGN, PA, LC, AJP. Performed the experiments: VHGN, PA, LC, AJP. Analyzed the data: VHGN, PA, LC, AJP. Contributed reagents/materials/analysis tools: VHGN, PA, LC, AJP. Wrote the paper: VHGN, PA, LC, AJP. 


\section{REFERENCES}

1. Balady GJ, Arena R, Sietsema K, Meyers J, Coke L, Fletcher GF, Forman D, Franklin B, Gazzi M, Gulati M, Keteyian SJ, Lavie CJ, Macko R, Mancini D, Milani RVClinician's Guide to Cardiopulmonary Exercise Testing in Adults: A Scientific Statement from American Hearth Association. Circulation 2010; 122(2): 191-225.

2. McLellan TM, Skinner JS. Submaximal endurance performance related to the ventilation thresholds. Can J Appl Sport Sci 1985; 10(2): 81-7.

3. Boulay MR, Simoneau JA, Lortie G, Bouchard C. Monitoring high-intensity endurance exercise with heart rate and thresholds. Med Sci Sports Exerc 1997; 1(29): 125-132.

4. Bosquet L, Léger L, Legros P. Methods to determine aerobic endurance. Sports Med 2002; 32(11): 675-693.

5. Myers J, Bellin D. Ramp Exercise Protocols for Clinical and Cardiopulmonary Exercise Testing. Sports Med 2000; 30(1): 23-29.

6. Davis JA, Whipp BJ, Lamarra N, Huntsman DJ, Frank MH, Wasserman K. Effect of ramp slope on determination of aerobic parameters from the ramp exercise test. Med Sci Sports Exerc 1982; 14(5): 339-343.

7. Anoula S, Rusko H. Reproducibility of aerobic and anaerobic thresholds in 20-50 year old men. Eur J Appl Physiol Occup Physiol 1984; 53(3): 260-266.

8. Faude O, Meyer T, Kindermann W. The Work Rate Corresponding to Ventilatory Threshold During Steady-State and Ramp Exercise. Int J Sports Physiol Perform 2006; 1(3): 222-232.

9. Porszasz J, Casaburi R, Somfay A, Woodhouse LJ, Whipp BJ. A treadmill ramp protocol using simultaneous changes in speed and grade. Med Sci Sports Exerc 2003; 35(9): 1596-603.

10. Neto VHG, Carletti L, Azevedo PHSM, Perez, AJ. Level of performance and stability of cardiopulmonary variables in the intensity of the ventilatory anaerobic threshold. Motriz: Rev Educ Fis 2018; 24(1): e1018133.

11. LaFontaine TP, Londeree BR, Spath WK. The maximal steady state versus selected running events. Med Sci Sports Exerc 1981; 13(3): 190-193.

12. Coyle EF, Gonzalez-Alonso J. Cardiovascular drift during prolonged exercise: New perspectives. Exerc Sports Sci Rev 2001; 2(29): 88-92.

13. Londeree BR. Effect of training on lactate/ventilatory thresholds: A meta-analysis. Med Sci Sports Exerc. 1997; 29(6): 837-43.

14. RibeiroJP, Hughes V, Fielding RA, Holden W, Evans W, Knuttgen HG. Metabolic and ventilatory responses to steady state exercise relative to lactate thresholds. Eur J Appl Physiol 1986, 55: 215-221.

15. Harriss DJ, Macsween A, Atkinson, G. Standards for Ethics in Sport and Exercise Science Research: 2018 Update. Int J Sports Med 2017; 38: 1126-1131

16. Billat V, Sirvent P, Lepretre PM, Koralzstein JP. Training effect on performance, substrate balance and blood lactate concentration at maximal lactate steady state in master endurance-runners. Eur J Appl Physiol 2004; 447(6): 875-883.

17. Howley ET, Basset DR, Welch HG. Criteria for maximal oxygen uptake: Review and commentary. Med Sci Sports Exerc 1995; 27(9): 1292-1301.

18. Beaver WLK, Wasserman K, Whipp BJ. New method for detecting anaerobic threshold by gas exchange. J Appl Physiol 1986; 6: 2020-2027.

19. Caiozzo VJ, Davis JA, Ellis JF, Azus JL, Vandagriff R, Prietto CA, McMaster WC. A comparison of gas exchange indices used to detect the anaerobic threshold. J Appl Physiol Respir Environ Exerc Physiol 1982; 53(5): 1184-1189.

20. Bland JM, Altman DG. Statistical methods for assessing agreement between two methods of clinical measurement. Lancet 1986; 1(8476): 307-310.

21. Giavarina D. Understanding Bland Altman analysis. Biochemia Med 2015; 25(2): 141-51. 
22. Lakens Daniel. Calculating and reporting effects size to facilitate cumulative science: a practical primer for t-tests and ANOVAs. Front Psychol 2013; 26(4): 1-12.

23. Bagger $M$, Petersen $P H$, Pedersen $P K$. Biological variation in variables associated with exercise training. Int J Sports Med 2003; 24(6): 433-440.

24. Denis C, Dormois D, Castells J, Bonnefoy R, Padilla S, Geyssant A, Lacour JR. Comparison of incremental and steady state tests of endurance training. Eur J Appl Physiol 1988; 57(4): 474-481.

25. Withers RT, Sherman WM, Miller JM, Costill DL. Specificity of the anaerobic threshold in endurance trained cyclists and runners. Eur J Appl Physiol 1981; 47(1): 93-104

26. Shimizu M, Myers J, Buchanan N, Whalsh D, Kraemer M, McAuley P, Froelicher VF. The ventilatory threshold: method, protocol, and evaluator agreement. Am Heart J 1991; 122(2): 509-516.

27. Hansen D, Dendale P, Berger J, Meeusen R. Low agreement of ventilatory threshold between training modes in cardiac patients. Eur J Appl Physiol 2007; 101(5): 547-554.

28. Keir DA, Paterson DH, Kowalchuk JM, Murias JM. Using ramp-incremental $\mathrm{V}$ O2 responses for constant-intensity exercise selection. Appl Physiol Nutr Metab. 2018; 43: 882-892.

29. Pallarés JG; Navarro RM; Ortega JF; Fernandez-Elıas VE; Rodriguez RM. Validity and Reliability of Ventilatory and Blood Lactate Thresholds in Well-Trained Cyclists. Plos One 2016; 11(9): 1-16.

30. Seiler KS, Kjerland GO. Quantifying training intensity distribution in elite endurance athletes: is there evidence for an optimal distribution? Scand J Med Sci Sports 2006; 16(1): 49-56.

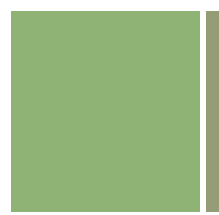

Corresponding author

Victor Hugo Gasparini Neto

Rua Nara Leão,125 - CEP: 29164-125, Serra

Espírito Santo - Brazil

E-mail: victorgasparini@gmail.com 